\title{
Association of variants in genes involved in environmental chemical metabolism and risk of cryptorchidism and hypospadias
}

\author{
Xian-Yang Qin ${ }^{1,2}$, Yoshiyuki Kojima ${ }^{3}$, Kentaro Mizuno ${ }^{3}$, Katsuhiko Ueoka ${ }^{4}$, Francesco Massart ${ }^{5}$, \\ Claudio Spinelli ${ }^{6}$, Hiroko Zaha ${ }^{1}$, Masahiro Okura ${ }^{1}$, Jun Yoshinaga ${ }^{2}$, Junzo Yonemoto ${ }^{1}$, Kenjiro Kohri ${ }^{3}$, \\ Yutaro Hayashi ${ }^{3}$, Tsutomu Ogata ${ }^{7,8}$ and Hideko Sone ${ }^{1}$
}

We hypothesized that single-nucleotide polymorphisms (SNPs) of genes involved in environmental endocrine disruptors (EEDs) metabolism might influence the risk of male genital malformations. In this study, we explored for association between 384 SNPs in 15 genes (AHR, AHRR, ARNT, ARNT2, NR1I2, RXRA, RXRB, RXRG, CYP1A1, CYP1A2, CYP1B1, CYP2B6, CYP3A4, CYP17A1 and CYP19A1) and risk of cryptorchidism (CO) and hypospadias (HS) in 334 Japanese (JPN) males (141 controls, $95 \mathrm{CO}$ and $98 \mathrm{HS}$ ) and 187 Italian (ITA) males (129 controls and $58 \mathrm{CO}$ ). In the JPN study group, five SNPs from ARNT2 (rs2278705 and rs5000770), CYP1A2 (rs2069521), CYP17A1 (rs4919686) and NR1/2 (rs2472680) were significantly associated at both allelic and genotypic levels with risk of at least one genital malformation phenotype. In the ITA study group, two SNPs in AHR ( $r s 3757824)$ and ARNT2 ( $r$ 1020397) were significantly associated with risk of CO. Interaction analysis of the positive SNPs using multifactor dimensionality reduction demonstrated that synergistic interaction between $r s 2472680$, rs4919686 and $r s 5000770$ had $62.81 \%$ prediction accuracy for $C O(P=0.011)$ and that between $r s 2069521$ and rs 2278705 had $69.98 \%$ prediction accuracy for HS $(P=0.001)$ in JPN population. In a combined analysis of JPN and ITA population, the most significant multi-locus association was observed between $r s 5000770$ and $r s 3757824$, which had $65.70 \%$ prediction accuracy for $\mathrm{CO}(P=\mathbf{0 . 0 5 5})$. Our findings indicate that genetic polymorphisms in genes involved in EED metabolism are associated with risk of $\mathrm{CO}$ and $\mathrm{HS}$.

Journal of Human Genetics (2012) 57, 434-441; doi:10.1038/jhg.2012.48; published online 31 May 2012

Keywords: cryptorchidism; cytochrome P450; endocrine disruptor; hypospadias; multifactor dimensionality reduction; nuclear receptor; SNP

\section{INTRODUCTION}

During the early stages of development (embryonic, fetal and infant), humans are highly vulnerable to environmental hazards. It has been proposed that in utero exposure to environmental endocrine disruptors (EEDs) could adversely affect fetal growth and induce several types of male genital malformation (MGM), such as cryptorchidism (CO) and hypospadias (HS). ${ }^{1,2}$ However, epidemiological studies on this issue have produced conflicting results. ${ }^{3-5}$ The effect of EEDs would depend on several factors, including the dosage of EED exposure, the developmental stage in which EED exposure occurred and inter-individual variability in genetic susceptibility to the effects of EED exposure.

The etiology of MGM seems to be multifactorial, involving genetic, hormonal and environmental factors. Single-nucleotide polymorphism (SNP) analyses have been undertaken in human populations and have identified multiple genetic variants that are linked with the prevalence of MGMs. The majority of the previous studies have been performed to exploit polymorphisms in sex hormone and endocrine-related genes, such as insulin-like factor 3 (INSL3), INSL3 receptor (LGR8 or GREAT), androgen receptor, estrogen receptors 1 and 2 (ESR1 and ESR2), steroid-5 $\alpha$-reductase, mastermind-like domain containing 1 (Cxorf6), activating transcription factor 3, fibroblast growth factor 8 and FGF receptor $2 .^{6-12}$

However, few of these studies have focused on polymorphisms in genes involved in drug metabolism that might influence individual susceptibility to exogenous agents such as EEDs. It is well known that both the metabolism of EEDs and male sexual differentiation are mediated by a series of transcription factors and cytochrome P450

${ }^{1}$ Research Center for Environmental Risk, National Institute for Environmental Studies, Tsukuba, Ibaraki, Japan; ${ }^{2}$ Department of Environmental Studies, University of Tokyo, Kashiwa, Chiba, Japan; ${ }^{3}$ Department of Nephro-Urology, Nagoya City University Graduate School of Medical Sciences, Nagoya, Aichi, Japan; ${ }^{4}$ Department of Surgical Subspecialties, National Research Center for Child Health and Development, Tokyo, Japan; ${ }^{5}$ Department of Pediatrics, University of Pisa, Pisa, Italy; ${ }^{6}$ Department of Surgery, University of Pisa, Pisa, Italy; ${ }^{7}$ Department of Endocrinology and Metabolism, National Research Institute for Child Health and Development, Tokyo, Japan and ${ }^{8}$ Department of Pediatrics, University Hospital, Hamamatsu University School of Medicine, Hamamatsu, Shizuoka, Japan

Correspondence: Dr H Sone, Research Center for Environmental Risk, National Institute for Environmental Studies, Tsukuba, Ibaraki 305-8506, Japan.

E-mail: hsone@nies.go.jp

Received 25 November 2011; revised 26 March 2012; accepted 18 April 2012; published online 31 May 2012 
(CYP) enzymes. Genetic polymorphisms in these transcription factors and enzymes may be important in determining individual susceptibility to EED exposure and also in the development of MGMs. ${ }^{13-14}$ Both our study, and other previous studies have identified that genetic variants for ESR1 and ESR2 could raise the susceptibility of CO and HS by enhancing the effects of estrogenic EEDs, which are known as xenoestrogens and currently the largest group of known EEDs. ${ }^{7,15}$ In addition, several nuclear receptors, such as aryl-hydrocarbon receptor (AHR) and pregnane $X$ receptor (PXR or NR1I2), are known to be crucial for EED-mediated CYP transcription. ${ }^{16}$ Previous studies have reported that polymorphisms in AHR may affect AHR functions, notably the induction of $C Y P 1$ genes, suggesting a potential role for nuclear receptor polymorphisms in the variable responses to xenobiotic chemicals. ${ }^{17}$ It is likely that further investigations of genetic polymorphisms involved in drug metabolism will shed increased light on the link between EED exposure and the development of MGMs.

Therefore, the aim of this study was to determine whether SNPs in genes involved in the metabolism of EEDs are associated with risk of $\mathrm{CO}$ and HS.

\section{MATERIALS AND METHODS}

\section{Study populations}

We conducted a case-control study in Japanese (JPN) and Italian (ITA) populations. The JPN study was based on a total of 334 genomic DNA samples collected at the Department of Molecular Endocrinology, National Research Institute for Child Health and Development, Tokyo, Japan, during the period 2002-2009. Samples were obtained from 193 male patients, aged 1-13 years; this group included $95 \mathrm{CO}$ patients and 98 HS patients; samples were also obtained from 141 control males, consisting of 75 boys, aged 4-16 years, with normal external genitalia and 66 adults, aged $24-50$ years, with proven fertility. The ITA study was based on a total of 187 genomic DNA samples collected at the Department of Pediatrics, University Hospital of Santa Chiara, Pisa, Italy, during the period 2006-2007. These samples were obtained from 58 CO patients, aged 1.0-2.2 years (median age 1.3 years), and 129 control males (median age 7.3 years).

All samples were obtained after written informed consent to participation in the study had been given.This study was approved by the Institutional Ethics Committees at the National Research Institute for Child Health, Japan and Development and National Institute for Environmental Studies, Japan.

\section{Gene selection}

KeyMolnet, a knowledge-based information system developed by the Institute of Medicinal Molecular Design Inc., Tokyo, Japan, was used to identify the molecular interactions of four nuclear receptors (AHR, PXR or NR1I2, ESR1 and ESR2). KeyMolnet is a bioinformatics database composed of manually curated information on relationships among human genes, molecules, diseases, pathways and drugs from selected review articles, literature and public databases. It can generate networks from any molecule and can connect the networks to biological phenomena, and to drug and disease information. ${ }^{18}$ From the generated network, CYP enzymes that are involved in the steroid hormone biosynthesis pathway were extracted for further analysis.

\section{SNP selection}

Selection of SNPs for use in this study was based on minor allele frequencies in the JPN populations with a location more than $60 \mathrm{~kb}$ distance from a range lying from $20 \mathrm{~kb}$ upstream of transcription to $10 \mathrm{~kb}$ downstream of each gene. They included known tagging SNPs, which are composed of a haplotype block.

\section{Genotyping}

The concentrations of the genomic DNA samples were determined with the PicoGreen dsDNA Quantitation kit according to manufacturer's protocol (Invitrogen, Carlsbad, CA, USA). SNPs were determined using the GoldenGate assay, which uses a human BeadArray technique (Illumina, San Diego,
CA, USA), and allele-specific fluorescence signals were scanned using a BeadScan500 (Illumina).

\section{Statistical analysis}

Genotype frequencies in controls were tested for concordance with the HardyWeinberg equilibrium using GeneSpring software, version 11.5 (Silicon Genetics, Redwood City, CA, USA). Differences in all genotype frequencies between cases and controls were tested for each SNP. Odds ratios (ORs) for disease risk and corresponding 95\% confidence intervals (CIs) were calculated at the genotypic level. The Cochran-Armitage trend test corrected with Benjamini-Hochberg false discovery rate and Fisher's exact test at the genotypic level were performed using GeneSpring software, version 11.5 (Silicon Genetics). In addition, multifactor dimensionality reduction (V2.0 Beta 8.4) analysis was performed to evaluate and validate main effects associated with the risk of $\mathrm{CO}$ and HS using a software package freely available online (www.epistasis.org). This algorithmic tool is a nonparametric (does not assume any statistical model) and model-free (no assumption mode of genetic inheritance) exploratory method, which has been developed to detect and characterize high-order gene-gene and gene-environment interactions in studies with relatively small sample size. ${ }^{19,20}$ Models are evaluated on the testing balanced accuracy, the cross-validation consistency and the statistical significance of the model. The testing balanced accuracy measures how often individuals are correctly classified with respect to their case/control status, and the cross-validation consistency evaluate the consistency with which individuals are classified. $.^{21} P<0.05$ was considered statistically significant in this study.

\section{RESULTS}

\section{Gene and SNP selection}

The molecular network was generated around four starting molecules (AHR, PXR or NR1I2, ESR1 and ESR2) within one path of both upstream and downstream from the starting point molecules by bioinformatics database tool (Figure 1). In addition to the four starting molecules, the generated network includes aryl-hydrocarbon receptor repressor (AHRR), aryl-hydrocarbon receptor nuclear translocator (ARNT), ARNT2, retinoid X receptor (RXR), and its three subtypes, RXRA, RXRB and RXRG, and 18 CYP enzymes. CYP enzymes involved in the steroid hormone biosynthesis pathway, which have been recognized as important targets for the actions of EEDs, ${ }^{22}$ namely CYP1A1, CYP1A2, CYP1B1, CYP2B6, CYP3A4, CYP17A1 and CYP19A1, were selected for further analysis. Therefore, a total of 15 genes were selected as target genes for analyzing SNPs in this study (Table 1a and $\mathrm{b}$ ). With the exception of RXRB, which had no tagging SNP, a total of 384 SNPs were detected in the remaining 14 genes.

\section{Polymorphisms and CO risk in the JPN study}

SNPs found to be associated with risk of CO in the JPN population are shown in Table 2. The minor homozygous rs5000770 (AA) of ARNT2, heterozygous rs4919686 (AC) of CYP17A1 and heterozygous rs247280 (AG) of NR1I2 were more frequently found in the $95 \mathrm{CO}$ patients than in the 141 controls $(\mathrm{OR}=3.5,95 \% \mathrm{CI}=1.7-7.3$; $\mathrm{OR}=3.3,95 \% \quad \mathrm{CI}=1.4-7.8 ;$ and $\mathrm{OR}=2.2,95 \% \mathrm{CI}=1.0-5.0$, respectively). Furthermore, the allele frequencies of these SNPs differed significantly between the $\mathrm{CO}$ patients and the controls $\left(P_{\text {trend }}<0.05\right)$

\section{Polymorphisms and HS risk in the JPN study}

The SNPs found to be associated with risk of HS in the JPN study group are shown in Table 3. Minor homozygous and heterozygous rs2069521 (AA and AG, respectively) of CYP1A2 and minor homozygous $r s 2278705$ (AA) and minor homozygous rs5000770 (AA) of ARNT2 were more frequently found in the $98 \mathrm{HS}$ patients than in the 141 controls $(\mathrm{OR}=4.5,95 \% \mathrm{CI}=9.3-194.6$; $\mathrm{OR}=3.7,95 \%$ 

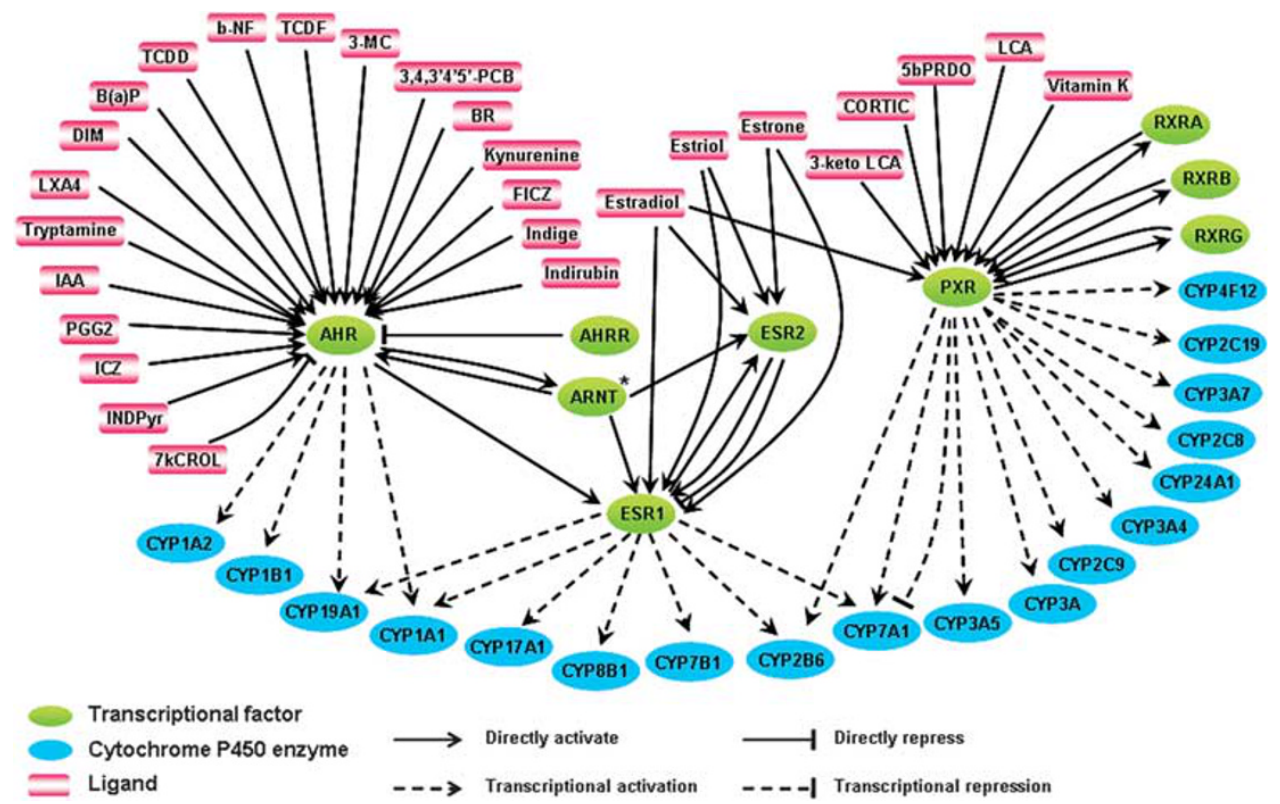

Figure 1 Network-based analysis for molecular interactions of AHR, PXR, ESR1 and ESR2 using KeyMolnet. A gene list of AHR, PXR, ESR1 and ESR2 was imported into KeyMolnet that generated a molecular network composed of 27 ligands (red), 9 transcription factors (green) and 18 cytochrome P450 enzymes (blue). Solid lines with an arrowhead and stop indicate direct activation and repression, respectively, including binding or phosphorylation. Dashed line with arrow and stop indicates stimulation and inhibition of gene expression, respectively. Asterisk $\left({ }^{*}\right)$ indicates ARNT2 in some cases according to the tissue-specific expression of ARNT and ARNT2.

\section{Table 1}

\begin{tabular}{|c|c|c|c|c|c|c|}
\hline $\begin{array}{l}\text { Gene } \\
\text { symbol }\end{array}$ & Aliases & Gene name & $\begin{array}{l}\text { Sequence } \\
\text { accession no. }\end{array}$ & Molecular function & SNPa & $\operatorname{tg} S N P^{b}$ \\
\hline \multicolumn{7}{|c|}{ (a) List of transcription factor genes and numbers of SNPS determined in this study } \\
\hline AHR & & Aryl-hydrocarbon receptor & $\begin{array}{l}\text { L19872, } \\
\text { NM_001621 }\end{array}$ & Nuclear receptor & 17 & 10 \\
\hline AHRR & KIAA1234 & Aryl-hydrocarbon receptor repressor & $\begin{array}{l}\text { AB033060, } \\
\text { NM_020731 }\end{array}$ & Nuclear receptor coactivator & 29 & 14 \\
\hline ARNT & HIF-1beta & $\begin{array}{l}\text { Aryl-hydrocarbon receptor nuclear } \\
\text { translocator }\end{array}$ & AF001307 & Nuclear receptor coactivator & 31 & 6 \\
\hline ARNT2 & KIAA0307, bHLHe1 & $\begin{array}{l}\text { Aryl-hydrocarbon receptor nuclear trans- } \\
\text { locator } 2\end{array}$ & AB002305 & Nuclear receptor coactivator & 69 & 32 \\
\hline NR112 & $\begin{array}{l}\text { ONR1, PXR, BXR, SXR, } \\
\text { PAR2 }\end{array}$ & $\begin{array}{l}\text { Nuclear receptor subfamily } 1 \text {, group I, } \\
\text { member } 2\end{array}$ & AF061056 & Nuclear receptor & 21 & 14 \\
\hline RXRA & NR2B1 & Retinoid $\mathrm{X}$ receptor, alpha & X52773 & Nuclear receptor & 46 & 19 \\
\hline RXRB & NR2B2, H-2RIIBP, RCoR-1 & Retinoid X receptor, beta & M84820 & Nuclear receptor & 0 & 0 \\
\hline RXRG & NR2B3 & Retinoid $\mathrm{X}$ receptor, gamma & $\begin{array}{l}\text { U38480, } \\
\text { NM_006917 }\end{array}$ & Nuclear receptor & 34 & 19 \\
\hline \multicolumn{7}{|c|}{ (b) List of CYP enzyme genes and numbers of SNPs determined in this study } \\
\hline CYP1A2 & P3-450, CP12 & $\begin{array}{l}\text { Cytochrome P450, family } 1 \text {, subfamily A, } \\
\text { polypeptide } 2\end{array}$ & $\begin{array}{l}\text { AF182274, } \\
\text { NM_000761 }\end{array}$ & $\begin{array}{l}\text { Drug metabolism enzyme; steroid hormone } \\
\text { biosynthesis enzyme }\end{array}$ & 10 & 2 \\
\hline CYP1B1 & CP1B & $\begin{array}{l}\text { Cytochrome } \mathrm{P} 450 \text {, family } 1 \text {, subfamily } B \text {, } \\
\text { polypeptide } 1\end{array}$ & $\begin{array}{l}\text { U56438, } \\
\text { NM_000104 }\end{array}$ & $\begin{array}{l}\text { Drug metabolism enzyme; steroid hormone } \\
\text { biosynthesis enzyme }\end{array}$ & 20 & 6 \\
\hline CYP2B6 & CPB6, CYPIIB6, CYP2B & $\begin{array}{l}\text { Cytochrome } \mathrm{P} 450 \text {, family } 2 \text {, subfamily } B \text {, } \\
\text { polypeptide } 6\end{array}$ & $\begin{array}{l}\text { AF182277, } \\
\text { NM_000767 }\end{array}$ & $\begin{array}{l}\text { Drug metabolism enzyme; steroid hormone } \\
\text { biosynthesis enzyme }\end{array}$ & 13 & 9 \\
\hline CYP3A4 & & $\begin{array}{l}\text { Cytochrome P450, family } 3 \text {, subfamily A, } \\
\text { polypeptide } 4\end{array}$ & AF280107 & $\begin{array}{l}\text { Drug metabolism enzyme; steroid hormone } \\
\text { biosynthesis enzyme }\end{array}$ & 27 & 1 \\
\hline CYP17A1 & P450C17, CPT7, S17AH & $\begin{array}{l}\text { Cytochrome P450, family } 17 \text {, subfamily } \\
\text { A, polypeptide } 1\end{array}$ & $\begin{array}{l}\text { M19489, } \\
\text { NM_000102 }\end{array}$ & $\begin{array}{l}\text { Drug metabolism enzyme; steroid hormone } \\
\text { biosynthesis enzyme }\end{array}$ & 18 & 4 \\
\hline CYP19A1 & $\begin{array}{l}\text { ARO, P-450AROM, CPV1, } \\
\text { ARO1, CYAR }\end{array}$ & $\begin{array}{l}\text { Cytochrome P450, family } 19 \text {, subfamily } \\
\text { A, polypeptide } 1\end{array}$ & D14473 & $\begin{array}{l}\text { Drug metabolism enzyme; steroid hormone } \\
\text { biosynthesis enzyme }\end{array}$ & 40 & 21 \\
\hline
\end{tabular}

aNumber of single-nucleotide polymorphisms (SNPs)

bNumber of tagging SNPs (tgSNPs). 
Table 2 Effect of ARNT2, CYP17A1 and NR1/2 polymorphisms on the risk of CO in the JPN study group

\begin{tabular}{|c|c|c|c|c|c|c|c|c|}
\hline \multirow[b]{2}{*}{ Gene } & \multirow[b]{2}{*}{ SNP } & \multirow[b]{2}{*}{ Genotype } & \multicolumn{2}{|c|}{ Case $(\mathrm{n}=95)$} & \multicolumn{2}{|c|}{ Control $(\mathrm{n}=141)$} & \multirow[b]{2}{*}{ OR $(95 \% C l)$} & \multirow[b]{2}{*}{$\mathrm{P}_{\text {trend }}{ }^{\mathrm{b}}$} \\
\hline & & & No. ${ }^{a}$ & $\%$ & No. & $\%$ & & \\
\hline \multirow[t]{15}{*}{ ARNT2 } & rs2278705 & GG & 66 & 70.21 & 104 & 74.28 & Reference & 0.141421 \\
\hline & & AA & 9 & 9.58 & 4 & 2.86 & $3.5(1.0-12.0)^{*}$ & \\
\hline & & $A G$ & 19 & 20.21 & 32 & 22.86 & $0.9(0.5-1.8)$ & \\
\hline & rs5000770 & GG & 40 & 42.11 & 78 & 55.32 & Reference & $0.002392^{\#}$ \\
\hline & & AA & 27 & 28.42 & 15 & 10.64 & $3.5(1.7-7.3)^{*}$ & \\
\hline & & $A G$ & 28 & 29.47 & 48 & 34.04 & $1.1(0.6-2.1)$ & \\
\hline & rs7183507 & GG & 60 & 63.83 & 97 & 68.79 & Reference & 0.121297 \\
\hline & & AA & 6 & 6.38 & 1 & 0.71 & $9.7(1.1-82.6)^{*}$ & \\
\hline & & $A G$ & 28 & 29.79 & 43 & 30.50 & $1.1(0.6-1.9)$ & \\
\hline & rs7178949 & AA & 58 & 63.04 & 97 & 68.79 & Reference & 0.0744634 \\
\hline & & GG & 7 & 7.61 & 1 & 0.71 & $11.7(1.4-97.6)^{*}$ & \\
\hline & & $A G$ & 27 & 29.35 & 43 & 30.50 & $1.1(0.6-1.9)$ & \\
\hline & rs1 1072922 & GG & 55 & 57.89 & 82 & 58.16 & Reference & 0.160607 \\
\hline & & AA & 14 & 14.74 & 4 & 2.84 & $5.2(1.6-16.7)^{*}$ & \\
\hline & & $A G$ & 26 & 27.37 & 55 & 39.00 & $0.7(0.4-1.3)$ & \\
\hline \multirow[t]{6}{*}{ CYP17A1 } & rs4919686 & AA & 75 & 81.52 & 131 & 93.57 & Reference & $0.0114102^{\#}$ \\
\hline & & $\mathrm{CC}$ & 0 & 0 & 0 & 0 & & \\
\hline & & $A C$ & 17 & 18.48 & 9 & 6.43 & $3.3(1.4-7.8)^{*}$ & \\
\hline & rs6163 & $A C$ & 31 & 39.74 & 72 & 51.43 & Reference & 0.0674834 \\
\hline & & AA & 13 & 16.67 & 28 & 20.00 & $1.1(0.5-2.4)$ & \\
\hline & & $\mathrm{CC}$ & 34 & 43.59 & 40 & 28.57 & $2.0(1.1-3.7)^{*}$ & \\
\hline \multirow[t]{6}{*}{$N R 1 / 2$} & rs1403526 & $A G$ & 26 & 30.23 & 66 & 46.81 & Reference & 0.697065 \\
\hline & & $A A$ & 40 & 46.51 & 51 & 36.17 & $2.0(1.1-3.7)^{*}$ & \\
\hline & & GG & 20 & 23.26 & 24 & 17.02 & $2.1(1.0-4.5)^{*}$ & \\
\hline & rs2472680 & GG & 76 & 82.61 & 128 & 91.43 & Reference & $0.0436642^{\#}$ \\
\hline & & $A A$ & 0 & 0 & 0 & 0 & & \\
\hline & & $A G$ & 16 & 17.39 & 12 & 8.57 & $2.2(1.0-5.0)^{*}$ & \\
\hline
\end{tabular}

Abbreviations: $\mathrm{Cl}$, confidence interval; CO, cryptorchidism; JPN, Japan; OR, odds ratio; SNP, single-nucleotide polymorphism.

${ }^{*} P<0.05$ in Fisher's exact test at genotypic level.

$\# P<0.05$ in Cochran-Armitage trend test corrected with Benjamini-Hochberg false discovery rate.

aData missing due to inability to amplify DNA.

b $P$-value in Cochran-Armitage trend test at allelic level.

$\mathrm{CI}=2.0-6.8 ; \quad \mathrm{OR}=7.2,95 \% \quad \mathrm{CI}=2.3-22.5 ; \quad$ and $\quad \mathrm{OR}=4.0,95 \%$ $\mathrm{CI}=1.9-8.5$, respectively). Furthermore, the allele frequencies of these SNPs differed significantly between the HS patients and the controls $\left(P_{\text {trend }}<0.05\right)$.

Polymorphisms and CO risk in the ITA study

The SNPs found to be associated with risk of CO in the ITA study group are shown in Table 4. Heterozygous rs3757824 (AG) of AHR and minor homozygous and heterozygous rs1020397 (CC and CG, respectively) of $A R N T 2$ were more frequently found in the $58 \mathrm{CO}$ patients than in the 129 controls $(\mathrm{OR}=3.1,95 \% \mathrm{CI}=1.6-6.1$; $\mathrm{OR}=3.4,95 \% \mathrm{CI}=1.3-8.9 ;$ and $\mathrm{OR}=2.8,95 \% \mathrm{CI}=1.3-5.8$, respectively). The allele frequencies of these SNPs also differed significantly different between $\mathrm{CO}$ patients and controls $\left(P_{\text {trend }}<0.05\right)$. None of the SNPs positively associated with CO risk were found to be common to both JPN and ITA populations.

Possible gene-gene interaction in predisposition of $\mathrm{CO}$ and $\mathrm{HS}$ Table 5 presents the potential gene-gene interaction in predisposition for CO and HS among the positive SNPs identified in this study using multifactor dimensionality reduction analysis. For all possible interactions among the positively and negatively associated SNPs, the most significant gene-gene interplay were $r s 2472680-r s 4919686-$ $r s 5000770$ with a $62.81 \%$ prediction accuracy for CO $(P=0.011)$ and rs2069521-rs2278705 with a $69.98 \%$ prediction accuracy for HS $(P=0.001)$ in JPN population. In a combined analysis of JPN and ITA population, a multi-locus association was observed between rs5000770 and $r s 3757824$, which had $65.70 \%$ prediction accuracy for $\mathrm{CO}(P=0.055)$.

\section{DISCUSSION}

This study was initiated to increase our understanding of the potential interaction of EED exposure and genetic factors on the risk of developing MGM. To achieve this aim, we sought to identify polymorphisms in genes involved in EED metabolism that were associated with an increased risk of CO and HS in a case-control study of populations from Japan and Italy.

One of our most interesting results concerned SNP rs5000770 of ARNT2. We observed a significant association at both allelic and genotypic levels between $r 5000770$ genotype and the risk of both CO and HS in the JPN study group. Patients with the AA genotype had a significant increase in CO and HS risk compared with those with the 
Table 3 Effect of CYP1A2, ARNT2, CYP17A1 and NR1I2 polymorphisms on the risk of HS in the JPN study group

\begin{tabular}{|c|c|c|c|c|c|c|c|c|}
\hline \multirow[b]{2}{*}{ Gene } & \multirow[b]{2}{*}{$S N P$} & \multirow[b]{2}{*}{ Genotype } & \multicolumn{2}{|c|}{ Case $(n=98)$} & \multicolumn{2}{|c|}{ Control $(n=141)$} & \multirow[b]{2}{*}{ OR $(95 \% \mathrm{Cl})$} & \multirow[b]{2}{*}{$\mathrm{P}_{\text {trend }} \mathrm{b}^{\mathrm{b}}$} \\
\hline & & & $\mathrm{No}^{\mathrm{a}}$ & $\%$ & No. & $\%$ & & \\
\hline \multirow{3}{*}{ CYP1A2 } & & $A A$ & 22 & 22.92 & 2 & 1.42 & $4.5(9.3-194.6)^{*}$ & \\
\hline & & $A G$ & 52 & 54.16 & 54 & 38.30 & $3.7(2.0-6.8)^{*}$ & \\
\hline & rs2069522 & AA & 70 & 81.40 & 128 & 91.43 & Reference & 0.0502541 \\
\hline \multirow[t]{5}{*}{ ARNT2 } & rs2278705 & $\mathrm{GG}$ & 61 & 62.89 & 104 & 74.29 & Reference & $0.0018348^{\#}$ \\
\hline & & $\mathrm{AA}$ & 17 & 17.53 & 4 & 2.86 & $7.2(2.3-22.5)^{*}$ & \\
\hline & & $A G$ & 19 & 19.59 & 32 & 22.85 & $1.0(0.5-1.9)$ & \\
\hline & rs5000770 & $\mathrm{GG}$ & 35 & 35.71 & 78 & 55.32 & Reference & $0.000249^{\#}$ \\
\hline & & $A A$ & 27 & 27.55 & 15 & 10.64 & $4.0(1.9-8.5)^{*}$ & \\
\hline \multirow[t]{3}{*}{ CYP17A1 } & rs17115149 & $\mathrm{CC}$ & 69 & 78.41 & 116 & 82.27 & Reference & 0.145118 \\
\hline & & $A A$ & 17 & 19.32 & 13 & 9.22 & $2.2(1.0-4.8)^{*}$ & \\
\hline & & $A C$ & 2 & 2.27 & 12 & 8.51 & $0.3(0.1-1.3)$ & \\
\hline \multirow[t]{3}{*}{$N R 1 / 2$} & rs2461823 & $A G$ & 33 & 36.26 & 67 & 47.52 & Reference & 0.58977 \\
\hline & & $A A$ & 17 & 18.68 & 15 & 10.64 & $2.3(1.0-5.2)^{*}$ & \\
\hline & & $\mathrm{GG}$ & 41 & 45.06 & 59 & 41.84 & $1.4(0.8-2.5)$ & \\
\hline
\end{tabular}

Abbreviations: $\mathrm{Cl}$, confidence interval; HS, hypospadias; JPN, Japan; OR, odds ratio; SNP, single-nucleotide polymorphism.

${ }^{*} P<0.05$ in Fisher's exact test at genotypic level.

$\# P<0.05$ in Cochran-Armitage trend test corrected with Benjamini-Hochberg false discovery rate.

aData missing due to inability to amplify DNA.

b $P$-value in Cochran-Armitage trend test at allelic level.

Table 4 Effect of AHR and ARNT2 polymorphisms on the risk of CO in the ITA study group

\begin{tabular}{|c|c|c|c|c|c|c|c|c|}
\hline \multirow[b]{2}{*}{ Gene } & \multirow[b]{2}{*}{$S N P$} & \multirow[b]{2}{*}{ Genotype } & \multicolumn{2}{|c|}{ Case $(\mathrm{n}=58)$} & \multicolumn{2}{|c|}{ Control $(\mathrm{n}=129)$} & \multirow[b]{2}{*}{ OR $(95 \% \mathrm{Cl})$} & \multirow[b]{2}{*}{$\mathrm{P}_{\text {trend }}{ }^{\mathrm{b}}$} \\
\hline & & & No. ${ }^{a}$ & $\%$ & No. & $\%$ & & \\
\hline \multirow[t]{3}{*}{$A h R$} & rs3757824 & AA & 27 & 46.55 & 93 & 72.09 & Reference & 0.0029 \\
\hline & & GG & 4 & 6.90 & 6 & 4.65 & $2.3(0.6-8.7)$ & \\
\hline & & $A G$ & 27 & 46.55 & 30 & 23.26 & $3.1(1.6-6.1)^{*}$ & \\
\hline \multirow[t]{3}{*}{ ARNT2 } & rs1020397 & GG & 13 & 22.41 & 59 & 45.74 & Reference & 0.0039 \\
\hline & & $\mathrm{CC}$ & 12 & 20.69 & 16 & 12.40 & $3.4(1.3-8.9)^{*}$ & \\
\hline & & CG & 33 & 56.90 & 54 & 41.86 & $2.8(1.3-5.8)^{*}$ & \\
\hline
\end{tabular}

Abbreviations: $\mathrm{Cl}$, confidence interval; $\mathrm{CO}$, cryptorchidism; ITA, Italian; OR, odds ratio; SNP, single-nucleotide polymorphism.

${ }^{*} P<0.05$ in Fisher's exact test at genotypic level.

aData missing due to inability to amplify DNA.

${ }^{b} P$-value in Cochran-Armitage trend test at allelic level.

GG genotype. Furthermore, synergistic interactions between rs5000770 and SNPs in NR1I2, CYP17A1, AHR and CYP1A2, which might confer susceptibility to both CO and HS in the JPN study group, were observed in the multifactor dimensionality reduction analysis. ARNT2 is a member of the basic helix-loop-helix PerARNT-SIM (bHLH-PAS) family of transcription factors that is involved in the regulation of many physiological pathways, including responses to environmental contaminants and oxygen deprivation, and for biological rhythms, angiogenesis and neuronal development. ${ }^{23-25}$ Arnt2 has pivotal roles in the regulation of early development in zebrafish. ${ }^{26}$ ARNT2 polymorphisms have been linked with the risk of some specific congenital malformations in humans such as cleft palate. ${ }^{27}$ However, little is known about the relationship of ARNT2 polymorphisms and the risk of MGM. Recently, a new concept has been suggested that testicular cancer, $\mathrm{CO}$ and some cases of HS and impaired spermatogenesis are symptoms of a single underlying entity that has been named the testicular dysgenesis syndrome..$^{28,29}$ This concept proposes the existence of a common underlying cause for the occurrence of these reproductive and developmental diseases, and suggests that adverse 
Table 5 Gene-gene interaction models for $\mathrm{CO}$ and HS

\begin{tabular}{|c|c|c|c|c|c|c|}
\hline Disease & Population & SNPs included ${ }^{\mathrm{a}}$ & Best model & $T B A$ & CVC & P-value \\
\hline \multirow[t]{6}{*}{$\mathrm{CO}$} & JPN population ${ }^{b}$ & SNPs significantly related with $\mathrm{CO}$ risk in JPN & SNP7 & 0.5318 & $7 / 10$ & 0.377 \\
\hline & & population (SNP4, 6, 7) & SNP6, 7 & 0.5999 & $8 / 10$ & 0.055 \\
\hline & & & SNP4, 6,7 & 0.6281 & $10 / 10$ & 0.011 \\
\hline & Combination of JPN and & SNPs significantly related with $\mathrm{CO}$ risk in & SNP5 & 0.5093 & $9 / 10$ & 0.828 \\
\hline & ITA populationc & JPN (SNP4, 6, 7) and ITA population (SNP1, 5) & SNP5, 7 & 0.657 & $10 / 10$ & 0.055 \\
\hline & & & SNP1, 5,7 & 0.5704 & $10 / 10$ & 0.055 \\
\hline \multirow[t]{3}{*}{ HS } & JPN population ${ }^{d}$ & SNPs significantly related with HS risk in & SNP2 & 0.6958 & $10 / 10$ & 0.001 \\
\hline & & JPN population ( $S N P 2,3,7)$ & SNP2, 3 & 0.6998 & $9 / 10$ & 0.001 \\
\hline & & & SNP2, 3,7 & 0.6576 & $10 / 10$ & 0.001 \\
\hline
\end{tabular}

Abbreviations: CO, cryptorchidism; CVC, cross-validation consistency; HS, hypospadias; JPN, Japan; ; ITA, Italian; SNP, single-nucleotide polymorphism; TBA, testing balanced accuracy.

$P$-values are from the sign test.

aSNP1: rs1020397 (ARNT2); SNP2: rs2069521 (CYP1A2); SNP3: rs2278705 (ARNT2); SNP4: rs2472680 (NR1I2); SNP5: rs3757824 (AHR); SNP6: rs4919686 (CYP17A1); SNP7:

rs5000770 (ARNT2).

$b_{n=236}(141$ controls and $95 \mathrm{CO})$

${ }^{c} n=423$ (270 controls and $\left.153 \mathrm{CO}\right)$.

$\mathrm{d}_{n}=239$ (141 controls and $98 \mathrm{HS}$ ).

environmental factors such as EEDs might exert their etiological impacts under a susceptible genetic background. Our result indicates that variations in ARNT2 may be one of the possible common causes. One possible interpretation of our findings is that the A allele of ARNT2 might influence individual responsiveness to EEDs, and increase the risk of $\mathrm{CO}$ and HS.

The SNP rs6163 of CYP17A1 is a common genetic polymorphism in the JPN population with a minor allele frequency of approximately $0.45 .^{30,31}$ In the JPN group studied here, individuals with $r s 6163 \mathrm{CC}$ genotype appeared to have an increased risk of CO. However, our statistical analysis suggested that the allele frequency difference between patients and controls for this SNP was only on the borderline of significance $\left(P_{\text {trend }}=0.067\right)$. It has been speculated that CYP17A1 variants might show differences in transcriptional efficiency and enzyme activity that, in turn, affect estrogen and androgen levels. ${ }^{32}$ CYP17A1 variants have been shown to be associated with increased risk of diseases in which estrogens or androgens have an important role, such as breast cancer and prostate cancer. ${ }^{33-35}$ Here we suggest that the $r s 6163$ genotype might affect androgen homeostasis during fetal life and, thereby, increase the risk of MGM as male sexual differentiation is critically dependent on normal androgen concentrations. ${ }^{36}$ At present, there is no information regarding any association between the rs6163 polymorphism and circulating hormone levels; however, another SNP ( $r$ 743572), which is also located in the $5^{\prime}$-untranslated region, has been extensively investigated and shown to be related to reduced messenger RNA levels in ovarian cells. ${ }^{32}$ In addition, we observed a significant association at both allelic and genotypic levels between the SNP rs4919686 for CYP17A1 with risk of CO in the JPN study group. However, this variant is much less common than $r s 6163$ and has only nine carriers in the control group.

The NR1I2 gene encodes the orphan nuclear receptor PXR, which has broad specificity and activates expression of CYP genes in response to a wide variety of xenobiotics. Following activation through ligand binding, PXR binds to the response element and induces the expression of CYP3A4, which has a major role in the hydroxylation of both estrone and estradiol. ${ }^{16}$ EEDs, especially those with estrogenic effects, may modulate estrogen levels through PXR signaling. Polymorphisms in genes involved in PXR signaling may modify the adverse effect of EED exposure on estrogen levels. In postmenopausal women, an interaction effect between NR1I2 gene variants and phytoestrogen exposure has been reported to influence circulating sex hormone levels. ${ }^{37}$ Our observation here that the heterozygous rs247280 genotype AG of NR1I2 is linked with an increased risk for CO in the JPN study group is consistent with this hypothesis. However, no significant association between CYP3A4 gene variants and risk of $\mathrm{CO}$ was found in this study.

The SNPs rs3757824 of AHR and rs1020397 of ARNT2 were associated with an increased risk of CO in the ITA study group but not in the JPN group. However, the interaction between $r s 3757824$ and another polymorphism of ARNT2 ( $r 55000770)$ seems to confer susceptibility to $\mathrm{CO}$ in a combined analysis of JPN and ITA population (65.70\% prediction accuracy, $P=0.055)$. Previous studies have reported that genetic polymorphisms in AHR signaling may affect the induction of CYP1A1 and can be related to the risk of endocrine-related diseases, such as breast cancer. ${ }^{38}$ A recent study has found a weak interaction effect between AHR $r s 3757824$ and environmental risk factors on colorectal neoplasia. ${ }^{39}$

The SNP rs2069521 of CYP1A2 was found to be significantly associated at both allelic and genotypic levels with risk of HS in JPN study group. CYP1A2 is one of the major CYP1 enzymes involved in the formation of catechol estrogens, which are known to be estrogenic and are thought to be carcinogenic. ${ }^{40}$ One possible explanation for this finding may be due to linkage disequilibrium with other genetic variants. CYP1A2 variants are in linkage disequilibrium with CYP1A1 alleles, which themselves have been previously associated with the risk of infertility and HS. ${ }^{13}$ Moreover, CYP1A1 and CYP1A2 share many of the same enzymatic activities and may be under coordinated regulation; placental expression and activity of CYP1A1 seem to be greater than for CYP1A2 and to occur earlier in pregnancy. ${ }^{41}$ However, we did not find any positive CYP1A1 variants in this study.

We did not find any genetic polymorphisms in common between the JPN and ITA study groups for risk of CO. Various possible factors may underlie the apparent absence of shared polymorphisms. One possible contributing factor is the low number of cases in our study (95 in the JPN group and 58 in the ITA group). Another factor may be the differences between ethnic groups in allele frequencies. Indeed, a somewhat similar result was found in investigations of the association of ESR1 polymorphisms and CO risk in these two ethnic groups. In the JPN study group, five SNPs in the $3^{\prime}$ region of the ESR 1 gene (the AGATA allele) were found to be overrepresented in cryptorchid patients in comparison with controls $(34.0$ versus 
$21.3 \%$ ), and homozygosity for this variant was found only in patients with undescended testes. ${ }^{42}$ By contrast, in the ITA study population, the AGATA haplotype was found to be associated with a reduced risk of CO. ${ }^{43}$ However, a rs5000770-rs3757824 interaction to susceptibility of $\mathrm{CO}$ was observed in the combined analysis of these two study groups. This interesting observation might explain partly the possible genetic effects masked by different gene-gene interaction leading to the controversial results in association studies, although further studies are necessary to confirm our findings in different ethnic groups.

Our study has several potential limitations that should be taken into consideration. First, as the study group sizes were relatively small, then the statistical power for the detection of subtle changes might have been limited. Second, we hypothesized that the impaired function of proteins encoded by susceptibility genes might be caused by genetic polymorphisms, and that such impaired function might increase the risk of development of CO and HS. However, little is known of whether such genetic polymorphisms actually affect protein and/or cell functions. Therefore, further studies are needed to confirm our findings and to explore the possible molecular mechanisms of our observations.

In conclusion, this study suggests that polymorphism of genes involved in the metabolism of EEDs might have a significant role in the risk of development of $\mathrm{CO}$ and HS. The genes that were studied function in dioxin binding ( $A H R$ and $A R N T 2)$, dioxin induction (CYP1A2), estrogen synthesis (CYP17A1) and bisphenol A induction (NR1I2), suggesting a possible link between EED exposure and the development of MGMs. Inter-individual polymorphic differences might cause variations in sensitivity to the effects of EEDs as a potential cause of MGMs.

\section{CONFLICT OF INTEREST}

The authors declare no conflict of interest.

\section{ACKNOWLEDGEMENTS}

This study was partly supported by the Environment Research and Technology Development Fund from the Ministry of the Environment, Japan, and by a grant for Research on Risk on Chemical Substances (H20-004) from the Ministry of Health, Labor, and Welfare of Japan. There is no other source of funding that has supported this study. We thank Dr Rie Taniguchi (Institute of Medicinal Molecular Design Inc., Tokyo, Japan) for technical support in gene target selection with KeyMolnet.

1 Vidaeff, A.C. \& Sever, L.E. In utero exposure to environmental estrogens and male reproductive health: a systematic review of biological and epidemiologic evidence. Reprod. Toxicol. 20, 5-20 (2005).

2 Martin, O.V., Shialis, T., Lester, J.N., Scrimshaw, M.D., Boobis, A.R. \& Voulvoulis, N. Testicular dysgenesis syndrome and the estrogen hypothesis: a quantitative metaanalysis. Environ. Health. Perspect. 116, 149-157 (2008)

3 Carbone, P., Giordano, F., Nori, F., Mantovani, A., Taruscio, D., Lauria, L. et al. The possible role of endocrine disrupting chemicals in the aetiology of cryptorchidism and hypospadias: a population-based case-control study in rural Sicily. Int. J. Androl. 30, 3-13 (2007).

4 Fernandez, M.F., Olmos, B., Granada, A., Lopez-Espinosa, M.J., Molina-Molina, J.M., Fernandez, J.M. et al. Human exposure to endocrine-disrupting chemicals and prenatal risk factors for cryptorchidism and hypospadias: a nested case-control study. Environ. Health. Perspect. 115(Suppl 1), 8-14 (2007).

5 Morales-Suarez-Varela, M.M., Toft, G.V., Jensen, M.S., Ramlau-Hansen, C., Kaerlev, L., Thulstrup, A.M. et al. Parental occupational exposure to endocrine disrupting chemicals and male genital malformations: a study in the danish national birth cohort study. Environ. Health 10, 3 (2011).

6 Sasaki, G., Ogata, T., Ishii, T., Kosaki, K., Sato, S., Homma, K. et al. Micropenis and the 5alpha-reductase-2 (SRD5A2) gene: mutation and V89L polymorphism analysis in 81 Japanese patients. J. Clin. Endocrinol. Metab. 88, 3431-3436 (2003).
7 Watanabe, M., Yoshida, R., Ueoka, K., Aoki, K., Sasagawa, I., Hasegawa, T. et al. Haplotype analysis of the estrogen receptor 1 gene in male genital and reproductive abnormalities. Hum. Reprod. 22, 1279-1284 (2007).

8 Willingham, E. \& Baskin, L.S. Candidate genes and their response to environmenta agents in the etiology of hypospadias. Nat. Clin. Pract. Urol. 4, 270-279 (2007).

9 Foresta, C., Zuccarello, D., Garolla, A. \& Ferlin, A. Role of hormones, genes, and environment in human cryptorchidism. Endocr. Rev. 29, 560-580 (2008).

10 Kojima, Y., Mizuno, K., Kohri, K. \& Hayashi, Y. Advances in molecular genetics of cryptorchidism. Urology 74, 571-578 (2009).

11 Kojima, Y., Kohri, K. \& Hayashi, Y. Genetic pathway of external genitalia formation and molecular etiology of hypospadias. J. Pediatr. Urol. 6, 346-354 (2010).

12 van der Zanden, L.F., van Rooij, I.A., Feitz, W.F., Vermeulen, S.H., Kiemeney, L.A., Knoers, N.V. et al. Genetics of hypospadias: are single-nucleotide polymorphisms in SRD5A2, ESR1, ESR2, and ATF3 really associated with the malformation? J. Clin. Endocrinol. Metab. 95, 2384-2390 (2010).

13 Kurahashi, N., Sata, F., Kasai, S., Shibata, T., Moriya, K., Yamada, H. et al. Maternal genetic polymorphisms in CYP1A1, GSTM1 and GSTT1 and the risk of hypospadias. Mol. Hum. Reprod. 11, 93-98 (2005).

14 Johansson, I. \& Ingelman-Sundberg, M. Genetic polymorphism and toxicology - with emphasis on cytochrome p450. Toxicol. Sci. 120, 1-13 (2011).

15 Ban, S., Sata, F., Kurahashi, N., Kasai, S., Moriya, K., Kakizaki, H. et al. Genetic polymorphisms of ESR1 and ESR2 that may influence estrogen activity and the risk of hypospadias. Hum. Reprod. 23, 1466-1471 (2008).

16 Waxman, D.J. P450 gene induction by structurally diverse xenochemicals: central role of nuclear receptors CAR, PXR, and PPAR. Arch. Biochem. Biophys. 369, 11-23 (1999).

17 Harper, P.A., Wong, J.Y., Lam, M.S. \& Okey, A.B. Polymorphisms in the human AH receptor. Chem. Biol. Interact 141, 161-187 (2002).

18 Sato, H., Ishida, S., Toda, K., Matsuda, R., Hayashi, Y., Shigetaka, M. et al. New approaches to mechanism analysis for drug discovery using DNA microarray data combined with KeyMolnet. Curr. Drug Discov. Technol. 2, 89-98 (2005).

19 Ritchie, M.D., Hahn, L.W., Roodi, N., Bailey, L.R., Dupont, W.D., Parl, F.F. et al. Multifactor-dimensionality reduction reveals high-order interactions among estrogenmetabolism genes in sporadic breast cancer. Am. J. Hum. Genet. 69, 138-147 (2001).

20 Lou, X.Y., Chen, G.B., Yan, L. Ma, J.Z., Zhu, J., Elston, R.C. et al. A generalized combinatorial approach for detecting gene-by-gene and gene-by-environment interactions with application to nicotine dependence. Am. J. Hum. Genet. 80, 1125-1137 (2007).

21 Binh, T.Q., Nakahori, Y., Hien, V.T., Khan, N.C., Lam, N.T., Mai le, B. et al. Correlations between genetic variance and adiposity measures, and gene $\times$ gene interactions for obesity in postmenopausal Vietnamese women. J. Genet. 90, 1-9 (2011).

22 Sanderson, J.T. The steroid hormone biosynthesis pathway as a target for endocrinedisrupting chemicals. Toxicol. Sci. 94, 3-21 (2006).

23 Hirose, K., Morita, M., Ema, M., Mimura, J., Hamada, H., Fujii, H. et al. cDNA cloning and tissue-specific expression of a novel basic helix-loop-helix/PAS factor (Arnt2) with close sequence similarity to the aryl hydrocarbon receptor nuclear translocator (Arnt). Mol. Cell. Biol. 16, 1706-1713 (1996).

24 Sekine, H., Mimura, J., Yamamoto, M. \& Fujii-Kuriyama, Y. Unique and overlapping transcriptional roles of arylhydrocarbon receptor nuclear translocator (Arnt) and Arnt2 in xenobiotic and hypoxic responses. J. Biol. Chem. 281, 37507-37516 (2006).

25 Hankinson, 0. Why does ARNT2 behave differently from ARNT? Toxicol. Sci. 103, 1-3 (2008)

26 Hill, A.J., Heiden, T.C., Heideman, W. \& Peterson, R.E. Potential roles of Arnt2 in zebrafish larval development. Zebrafish 6, 79-91 (2009).

27 Barrow, L.L., Wines, M.E., Romitti, P.A., Holdener, B.C. \& Murray, J.C. Aryl hydrocarbon receptor nuclear translocator 2 (ARNT2): structure, gene mapping, polymorphisms, and candidate evaluation for human orofacial clefts. Teratology 66 85-90 (2002).

28 Skakkebaek, N.E., Rajpert-De Meyts, E. \& Main, K.M. Testicular dysgenesis syndrome: an increasingly common developmental disorder with environmental aspects. Hum. Reprod. 16, 972-978 (2001).

29 Jorgensen, N., Meyts, E.R., Main, K.M. \& Skakkebaek, N.E. Testicular dysgenesis syndrome comprises some but not all cases of hypospadias and impaired spermatogenesis. Int. J. Androl. 33, 298-303 (2010)

30 Yoshimura, K. Hanaoka, T, Ohnami, S., Kohno, T, Liu, Y., Yoshida, T et al. Allele frequencies of single nucleotide polymorphisms (SNPs) in 40 candidate genes for gene-environment studies on cancer: data from population-based Japanese random samples. J. Hum. Genet. 48, 654-658 (2003).

31 Ikeda, S., Sasazuki, S., Natsukawa, S., Shaura, K., Koizumi, Y, Kasuga, Y et al. Screening of 214 single nucleotide polymorphisms in 44 candidate cancer susceptibility genes: a case-control study on gastric and colorectal cancers in the Japanese population. Am. J. Gastroenterol. 103, 1476-1487 (2008).

32 Sharp, L., Cardy, A.H., Cotton, S.C. \& Little, J. CYP17 gene polymorphisms: prevalence and associations with hormone levels and related factors. a HuGE review. Am. J. Epidemiol. 160, 729-740 (2004).

33 Chen, Y., Gammon, M.D., Teitelbaum, S.L., Britton, J.A., Terry, M.B., Shantakumar, S. et al. Estrogen-biosynthesis gene CYP17 and its interactions with reproductive, hormonal and lifestyle factors in breast cancer risk: results from the Long Island Breast Cancer Study Project. Carcinogenesis 29, 766-771 (2008).

34 Wang, J.F. \& Chou, K.C. Molecular modeling of cytochrome P450 and drug metabolism. Curr. Drug. Metab. 11, 342-346 (2010).

35 Wright, J.L., Kwon, E.M., Lin, D.W., Kolb, S., Koopmeiners, J.S., Feng, Z. et al. CYP17 polymorphisms and prostate cancer outcomes. Prostate 70, 1094-1101 (2010) 
36 Holmes, N.M., Miller, W.L. \& Baskin, L.S. Lack of defects in androgen production in children with hypospadias. J. Clin. Endocrinol. Metab. 89, 2811-2816 (2004).

37 Low, Y.L., Dunning, A.M., Dowsett, M., Folkerd, E., Doody, D., Taylor, J. et al. Phytoestrogen exposure is associated with circulating sex hormone levels in postmenopausal women and interact with ESR1 and NR1I2 gene variants. Cancer Epidemiol. Biomarkers Prev. 16, 1009-1016 (2007).

38 Long, J.R., Egan, K.M., Dunning, L., Shu, X.O., Cai, Q., Cai, H. et al. Population-based case-control study of AhR (aryl hydrocarbon receptor) and CYP1A2 polymorphisms and breast cancer risk. Pharmacogenet. Genomics 16, 237-243 (2006).

39 Wang, H., Yamamoto, J.F., Caberto, C., Saltzman, B., Decker, R., Vogt, T.M. et al. Genetic variation in the bioactivation pathway for polycyclic hydrocarbons and heterocyclic amines in relation to risk of colorectal neoplasia. Carcinogenesis 32, 203-209 (2011).
40 Clemons, M. \& Goss, P. Estrogen and the risk of breast cancer. N. Engl. J. Med. 344, 276-285 (2001).

41 Syme, M.R., Paxton, J.W. \& Keelan, J.A. Drug transfer and metabolism by the human placenta. Clin. Pharmacokinet. 43, 487-514 (2004).

42 Yoshida, R., Fukami, M., Sasagawa, I., Hasegawa, T., Kamatani, N. \& Ogata, T. Association of cryptorchidism with a specific haplotype of the estrogen receptor alpha gene: implication for the susceptibility to estrogenic environmental endocrine disruptors. J. Clin. Endocrinol. Metab. 90, 4716-4721 (2005).

43 Galan, J.J., Guarducci, E., Nuti, F., Gonzalez, A., Ruiz, M., Ruiz, A. et al. Molecular analysis of estrogen receptor alpha gene AGATA haplotype and SNP12 in European populations: potential protective effect for cryptorchidism and lack of association with male infertility. Hum. Reprod. 22, 444-449 (2007). 